\title{
EXPERIMENTAL TRANSMISSION OF MINOR RESPIRATORY ILL- NESS TO HUMAN VOLUNTEERS BY FILTER-PASSING AGENTS. I. DEMONSTRATION OF TWO TYPES OF ILLNESS CHARACTERIZED BY LONG AND SHORT INCUBATION PERIODS AND DIFFERENT CLINICAL FEATURES 1
}

\author{
BY THE COMMISSION ON ACUTE RESPIRATORY DISEASES 2 \\ (From the Respiratory Diseases Commission Laboratory, Regional Hospital, Fort Bragg, N. C.) ${ }^{\mathrm{s}}$
}

(Received for publication March 3, 1947)

\section{INTRODUCTION}

Investigations of respiratory disease in military populations, and to a less extent in civilian life, have consistently demonstrated that a large majority of the respiratory illnesses are of unknown etiology (1 to 10). Clinical and epidemiological studies have indicated points of similarity and of difference in selected groups of such cases $(1,6$, 11,12 ), but in the absence of laboratory confirmation, it has been almost impossible to segregate distinct entities. In the Army, for example, studies in the field, in dispensaries, and in the hospital $(13,14)$ have shown variations in the clinical picture from mild, "coryzal" types of infection, resembling the "common cold," to severe, "grippelike" illnesses, either with or without pulmonary infiltration. Similarly, epidemiological observa-

1 This investigation was supported through the Commission on Acute Respiratory Diseases, Board for the Investigation and Control of Influenza and Other Epidemic Diseases in the Army, Preventive Medicine Service, Office of the Surgeon General, United States Army, and by grants from the Commonwealth Fund, the W. K. Kellogg Foundation, the John and Mary R. Markle Foundation, and the International Health Division of the Rockefeller Foundation, to the Board for the Investigation and Control of Influenza and Other Epidemic Diseases, for the Commission on Acute Respiratory Diseases.

2 Members and professional associates of the Commission on Acute Respiratory Diseases were: John $\mathbf{H}$. Dingle, Lt. Col., M.C., A.U.S., Director; Theodore J. Abernethy, Lt. Col., M.C., A.U.S.; George F. Badger, Major, M.C., A.U.S.; Joseph W. Beard, M.D.; Norman L. Cressy, Major, M.C., A.U.S.; A. E. Feller, M. D.; Irving Gordon, M.D.; Alexander D. Langmuir, Major, M.C., A.U.S.; Charles H. Rammelkamp, Jr., M.D.; Elias Strauss, Major, M.C., A.U.S.

8 Now located in the Department of Preventive Medicine, School of Medicine, Western Reserve University, Cleveland, Ohio. tions have revealed waves of mild respiratory infections, chiefly resembling the "common cold," in the summer and fall (13) and epidemics of more severe disease, apparently associated with an increased incidence of primary atypical pneumonia, in the winter and spring $(2,13,15)$. Laboratory studies have failed to reveal causative agents in these cases, although human volunteer experiments have suggested a relationship between minor respiratory illness and primary atypical pneumonia (16 to 18 ).

A more direct attempt (a) to segregate "entities" from this group of unclassified respiratory illnesses and $(b)$ to clarify the relation between minor respiratory illnesses and primary atypical pneumonia has been made by a series of experiments in human volunteers. Four donor subjects were selected whose illnesses appeared clinically to represent different types of respiratory disease:

(1) A relatively severe febrile illness, with sore throat, hoarseness and cough, in a recruit; referred to here as "acute respiratory disease" (ARD),

(2) A coryzal illness, with fever and constitutional symptoms, in a laboratory officer, referred to here as "severe common cold" (S-CC),

(3) A mild coryzal illness, without fever, in a medical officer, referred to here as "common cold" (CC), and

(4) A severe febrile illness, with marked constitutional symptoms and rales in the lungs, in a recruit, referred to here as "bronchitis resembling atypical pneumonia" (Br-AP).

Filtered washings from the respiratory tracts of these 4 donors, inoculated into 4 groups of volunteers, induced 2 types of minor respiratory ill- 
ness as indicated by clinical characteristics and incubation periods. The results are reported in the present paper.

Further differentiation of these 2 types of minor respiratory illness was achieved on the basis of active immunity by reinoculation of the volunteers with homologous and heterologous washings from the donors. Finally, it was determined that primary atypical pneumonia could still be induced in individuals convalescent from both types of disease. These findings are presented in the second paper.

\section{Terminology}

Inadequate knowledge of causation of the respiratory illnesses dealt with in this paper results unavoidably in cumbersome nomenclature. The terms and abbreviations employed here are used in an attempt to name the individual illnesses which were selected for study because they might represent entities and to relate those illnesses, insofar as possible, to cases observed in previous investigations.

Undifferentiated acute respiratory disease $(A R D)$. This term is applied to an acute febrile respiratory disease of short duration characterized by constitutional reactions or local respiratory symptoms, or both, of sufficient severity to require hospitalization, ${ }^{4}$ and by epidemic occurrence among recruits in the winter months $(2,14,15)$. The etiology is unknown. The diagnosis is made by exclusion, based on: (1) the absence of clinical or serological evidence of streptococcal infection or specific contagious disease; (2) absence of pulmonary consolidation, as determined by roentgenogram; and (3). absence of serological evidence of influenza $\mathrm{A}$ or $\mathrm{B}$.

Severe common cold $(S-C C)$. This name indicates a respiratory illness characterized by coryza, constitutional symptoms and fever. With respect to the particular donor used in the present experiments, the term was applied retrospectively at the end of the study because of the difficulty in classifying his illness clinically as an instance of "acute respiratory disease" or of "common cold."

Common cold $(C C)$. This term refers to a respiratory infection characterized principally by

\footnotetext{
4 In the Army the usual criterion for hospitalization was a temperature of $100^{\circ} \mathrm{F}$. or higher.
}

coryza, minimal constitutional symptoms and little or no fever.

Bronchitis resembling atypical pneumonia $(\mathrm{Br}-$ $A P)$. This term is used to describe a febrile respiratory disease in which the character of onset, physical findings, including rales in the lungs, and clinical course of illness are similar to those observed in primary atypical pneumonia; roentgenographic evidence of pulmonary consolidation, however, is lacking (1).

Minor respiratory illness $(M R I)$. This phrase is employed as a general term to indicate those respiratory illnesses, occurring among the recipients in these and previous experiments (16 to 18 ), which were characterized by variable clinical patterns and absence of roentgenographic evidence of pulmonary consolidation. The term has also been used in previous publications $(13,15)$ to designate a mild, usually afebrile respiratory infection which was observed among recruits on duty and in dispensaries, but which did not require hospitalization.

\section{METHODS AND MATERIALS}

The experiments were performed in the same hotel utilized for previous studies. In general, the selection of volunteers, isolation precautions, clinical and laboratory examinations and inoculation procedures were the same as those employed the year before in the third experiment of the series (18). Each volunteer was isolated in an individual room during the entire experimental period in order to prevent chance exposure to respiratory diseases through outside contact. A control period of isolation of not less than 2 weeks preceded the inoculation of each individual. The techniques of a contagious hospital were instituted; gowns and face masks were worn at all times by the attending staff.

Subjects. Thirty-seven volunteers comprised the first study group. These men were observed during a 7-week period from May 17 to July 5, 1945. At the completion of this study 16 of the original group volunteered to remain in isolation for an additional 7 weeks; the remaining 23 men were released from observation and 25 replacements secured. The second half of the study was conducted during the 7-week period from July 11 to August 31,$1945 ; 41$ volunteers comprised the experimental group. None of the volunteers had participated in previous investigations performed in 1943 or 1944.

Laboratory Studies. Complete blood counts using capillary blood were done at the beginning of the isolation period. Total and differential leukocyte counts were obtained subsequently at 3- or 4-day intervals. The erythrocyte sedimentation rate was determined weekly by the Rourke-Ernstene method (19).

Venous blood was taken at weekly intervals for the following tests: cold hemagglutination (20), antistrep- 
tolysin (21), heterophile antibody (22) and agglutinininhibition tests for influenza viruses $A$ and $B$ (23). From 4 to 6 specimens were obtained from each individual during any given study period. Specimens from each subject were always tested at the same time at the conclusion of the experiment.

Bacteriological study of the throat flora was made on each volunteer and on each member of the attending staff every second day. Swab cultures of the pharynx and tonsils or tonsillar fossae were taken before breakfast, placed immediately in $5 \mathrm{ml}$. of sterile broth and subsequently plated on blood agar according to a standard technique (24). Every 4th day an additional throat swab was obtained and placed in media selective for the cultivation of Beta-hemolytic streptococci (25). The presence or absence and relative frequency of the following organisms were recorded: Beta-hemolytic streptococcus, Staphylococcus aureus, pneumococcus, Hemophilus influenzae, $H$. hemolyticus, Friedländer's bacillus, and gram-negative cocci. The usual mouse technique was employed for the detection of pneumococci. Anaerobic cultures were not performed.

Inocula. The inocula consisted of nasal and pharyngeal washings obtained from each of the 4 donor subjects during the acute stage of illness and from each of nine well persons in a control group. The inocula were prepared in the following manner: Several specimens of nasal and pharyngeal washings in sterile broth were collected from each donor, frozen immediately and stored at $-70^{\circ}$ C. A few days prior to inoculation, the individual specimens from each donor were thawed rapidly in a $37^{\circ} \mathrm{C}$. waterbath and pooled. After manual shaking or homogenization in a Waring blendor, the material was centrifugalized at 4,500 r.p.m. for 10 minutes in an angle centrifuge, and the sediment discarded. Approximately half of the supernate was filtered through Corning "UF" fritted glass filters and half through single-pad Seitz filters. All procedures were carried out in the cold. Specimens from each filter were placed in separate Pyrex Erlenmyer flasks, a portion was reserved for bacteriological study and the balance of the filtrate refrozen and stored at $-70^{\circ} \mathrm{C}$. until ready for use. Aerobic and anaerobic cultures of the several specimens of filtrate were made on blood-agar plates, and in blood broth and thioglycolate medium. All filtrates proved to be sterile, so that none had to be discarded. On the day of inoculation the specimens were thawed rapidly, kept iced and used in proportion of approximately 1 part Corning filtrate to 1 part Seitz filtrate.

Inoculation procedures. Five groups of men, A, B, C, $D$ and $E$, were given inoculations of various types of filtrate on different days (Table I). The inoculations were given out-of-doors and sterile precautions were used throughout.

Each volunteer received a total inoculum of $10 \mathrm{ml}$. administered in 3 equal doses during the morning and afternoon of a single day. Approximately $2.5 \mathrm{ml}$. was given by nebulizer and $7.5 \mathrm{ml}$. by atomizer. The material was sprayed into the nose-and throat in synchronization with deep inspiration; a tank of nitrogen served as a source of pressure. Comparable techniques were maintained, not only in the separate inoculations of a given day, but also in those given on different days.

Treatment. The treatment of patients was symptomatic. Antipyretic or antibacterial drugs were not used. Nasal instillation of sympathomimetic drugs was avoided. Codeine sulphate and phenobarbital were administered to control headache, cough or restlessness. Barbiturates were used freely as sedatives.

\section{RESULTS}

\section{Inoculation of autogenous filtrates (control)}

Separate autogenous filtrates were prepared, using pharyngeal and nasal washings collected from each of 9 individuals after 9 and 11 days in isolation, respectively. Such inocula were employed in order (1) to assess the mechanical effects of the spraying procedures, (2) to demonstrate the possible existence of a latent agent, and (3) to avoid the selection, as "control" donors, of apparently normal individuals who might be actually harboring an agent. After a total period of 14 days of isolation, each volunteer was inoculated with his own filtrate (Group A, Table II).

\section{TABLE I}

Types of illness in donors of the inocula administered to the volunteers in the various groups

\begin{tabular}{|c|c|c|c|c|}
\hline Group & $\underset{\substack{\text { Number } \\
\text { of } \\
\text { men }}}{ }$ & $\begin{array}{l}\text { Date } \\
\text { of inoc- } \\
\text { ulation }\end{array}$ & Types of illness in donors* & $\begin{array}{l}\text { Code } \\
\text { desig- } \\
\text { nation }\end{array}$ \\
\hline $\begin{array}{l}\text { A } \\
\text { B }\end{array}$ & $\begin{array}{r}9 \\
14\end{array}$ & $\begin{array}{l}5 / 31 / 45 \\
6 / 8 / 45\end{array}$ & $\begin{array}{c}\text { None } \\
\text { "Acute respiratory }\end{array}$ & $\begin{array}{l}\text { Control } \\
\text { ARD }\end{array}$ \\
\hline $\begin{array}{l}\mathrm{C} \\
\mathrm{D} \\
\mathrm{E}\end{array}$ & $\begin{array}{l}14 \\
10 \\
10\end{array}$ & $\begin{array}{l}6 / 11 / 45 \\
7 / 27 / 45 \\
7 / 26 / 45\end{array}$ & $\begin{array}{l}\text { "Severe common cold" } \\
\text { "Common cold" } \\
\text { "Bronchitis resembling } \\
\text { atypical pneumonia" }\end{array}$ & $\begin{array}{c}\text { S-CC } \\
\text { CC } \\
\text { Br-AP }\end{array}$ \\
\hline
\end{tabular}

* See text for definitions of the illnesses.

TABLE II

Summary of results in 48 volunteers inoculated with filtrates from cases of respiratory disease and in 9 controls inoculated with autogenous filtrates

\begin{tabular}{c|c|c|c|c|c}
\hline \hline Group & $\begin{array}{c}\text { Type } \\
\text { of } \\
\text { inoculum* }\end{array}$ & $\begin{array}{c}\text { Days of } \\
\text { isolation } \\
\text { prior to } \\
\text { inocula- } \\
\text { tion }\end{array}$ & $\begin{array}{c}\text { Number } \\
\text { of } \\
\text { men }\end{array}$ & \multicolumn{2}{|c|}{ Results } \\
\cline { 4 - 6 } & MRI & $\begin{array}{c}\text { No } \\
\text { illnews }\end{array}$ \\
\hline B & Control & 14 & 9 & 0 & 9 \\
C & ARD & 22 & 14 & 12 & 2 \\
D & S-CC & 25 & 14 & 9 & 5 \\
E & CCC & 17 & 10 & 6 & 4 \\
\hline
\end{tabular}

MRI = Minor respiratory illness.

* See Table I and text for explanation of code designations. 
Of the 9 volunteers given autogenous filtrates all remained well for a period of 30 days following inoculation (Table II). In no instance were symptoms or physical signs indicative of respiratory disease observed.

\section{Inoculation of $A R D$ filtrate}

On June 8, after a control period of 22 days, 14 volunteers received ARD filtrate (Group B, Table II). The donor of this filtrate had suffered a moderately severe respiratory illness comparable to the "undifferentiated acute respiratory disease" of recruits $(2,14,15)$. Pertinent data regarding the illness are given below and shown graphically in Figure 1.

The patient $(\mathrm{NE})$ was an 18-year-old soldier with 5 weeks of Army service. He was well until the evening of May 7, at which time he became feverish, drowsy and developed a sore throat. The following morning these symptoms were still present and he was admitted to the hospital. The temperature on admission was $102.8^{\circ} \mathrm{F}$., the pulse rate, 124, and the respiratory rate, 24 . He appeared moderately ill. Physical examination revealed palpable non-tender cervical lymph nodes, slight nasal discharge (which was no more than normal for the patient), and mild injection of the soft palate, pharynx and tonsils.
The tonsils were not conspicuously enlarged; exudate was not present. The lungs were clear. Roentgenograms of the chest taken in posterior-anterior and oblique positions showed no consolidation. Sinus films showed polypoid thickening of both antra, but no evidence of acute infection.

The febrile period was of 2 days' duration. Sore throat and later, hoarseness and cough, were the most prominent symptoms noted. By the 6th day all symptoms had disappeared. Convalescence was uneventful.

The total leukocyte count was normal. Bacteriological studies performed during the first 3 days from throat swabs, and from throat and nasal washings showed $H$. influenzae and $H$. hemolyticus. Serological tests were made on 4 samples of serum obtained at weekly intervals from admission; these tests included cold hemagglutination, heterophile agglutination, antistreptolysin " $O$ " titers and antibody determinations for influenza viruses $\mathrm{A}$ and $\mathrm{B}$. None of these tests revealed findings of diagnostic significance.

Of the 14 volunteers inoculated with ARD filtrate, 12 developed minor respiratory illness and 2 remained well (Table II). None of the group developed primary atypical pneumonia.

In 9 individuals, symptoms were first observed on the 5 th or 6 th day after inoculation. In the remaining 3 cases, onset of illness occurred on the 3 rd, 8 th and 9 th days, respectively.

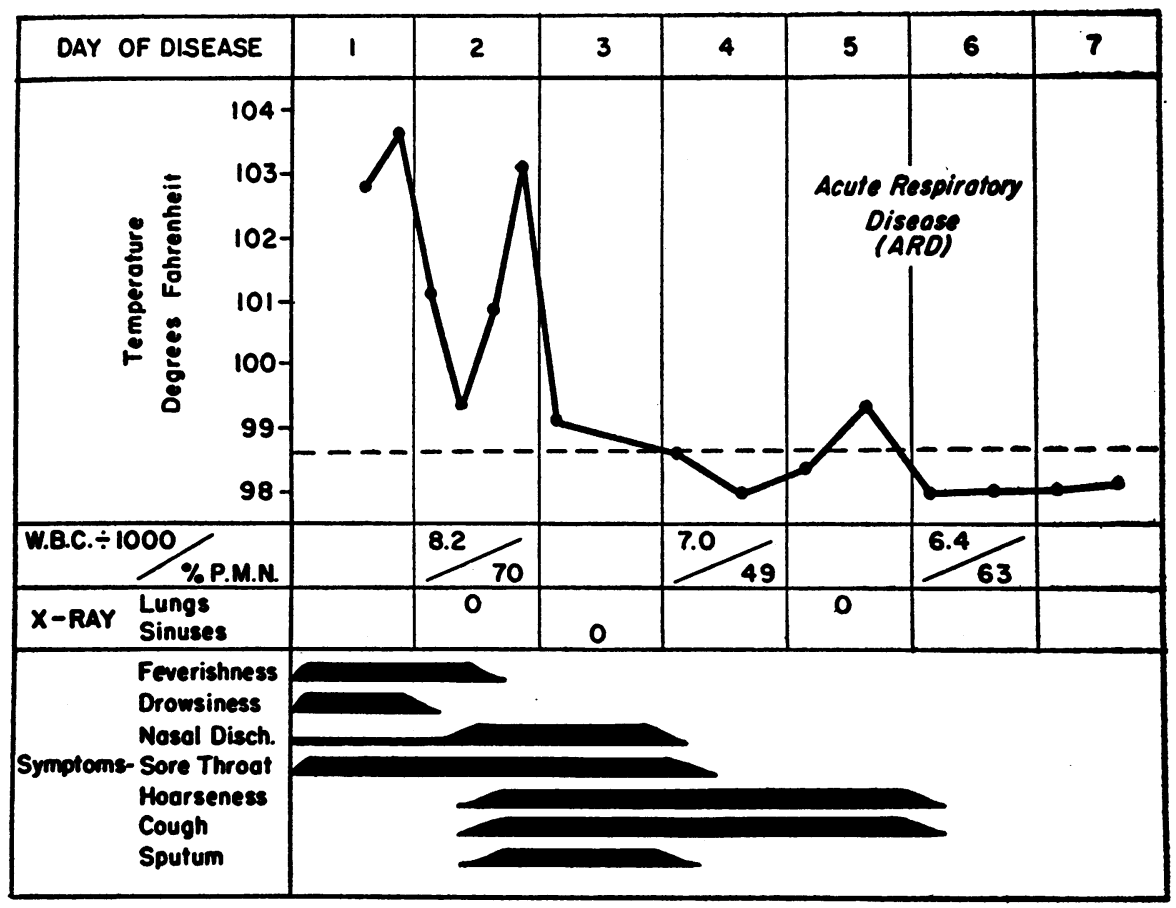

Fig. 1. Clinical Chart of Donor Whose Illness was Termed Acute Respiratory Disease (ARD) 
The clinical pattern observed in these cases was variable. In general the illnesses were mild in nature, with minimal constitutional symptoms, and varying degrees of symptoms and signs referable to upper respiratory tract. In 7 patients the duration of illness was no more than 4 days; in 5 patients it lasted between 6 and 12 days. Fever was not a conspicuous feature in any of the subjects; none had as brisk a febrile response to illness as did the donor.

The onset of illness was usually characterized by the development of dry or sore throat during the course of 24 or 48 hours. Generally, there were accompanying signs of mild inflammation of the soft palate or pharynx (injection or lymphoid hyperplasia). Nasal symptoms (sneezing, obstruction and discharge) were frequent during the first 48 hours from onset, but were of minimal intensity and not associated with obvious signs of nasal obstruction or coryza. Hoarseness and cough were observed at some time by approximately half of the patients, but were not conspicuous features of the early course of illness.

The following case reports illustrate the characteristics of the illnesses following inoculation of ARD material.

Case No. RP3-331. Five days after inoculation this patient first observed sore throat which was unaccompanied by constitutional or other local symptoms. During the next 24 hours there was minimal nasal obstruction and discharge as well as soreness of the throat. Physical examination revealed only prominent pharyngeal lymphoid follicles. On the 3rd day of illness he complained of headache; there was improvement in nasal symptoms, but no lessening of throat symptoms. The cervical lymph nodes were tender, but not conspicuously enlarged. $\mathrm{Na}$ sal obstruction was of moderate degree. There was gradual improvement in symptoms and signs, and all evidences of illness disappeared by the 7th day. The maximum temperature was $99.8^{\circ} \mathrm{F}$. on the day after onset of symptoms, or 6 days after inoculation.

The total and differential leukocyte counts showed no alteration following inoculation. There was no elevation of the erythrocyte sedimentation rate at any time. Serological procedures showed no diagnostic increase in antibodies to influenza viruses $A$ or $B$, heterophile agglutinins, or cold hemagglutinins. Beta-hemolytic streptococcus, group C, was isolated from throat cultures before and after inoculation, but no diagnostic rise of antistreptolysins was demonstrated in the patient's serum during convalescence.

Case No. RP3-321. This 26-year-old subject gave 2 history of infrequent mild respiratory infections of short duration occurring once a year, and consisting of sore throat, nasal congestion and coryza. He had had no respiratory illness in the previous 8 , months. Beginning 6 days after inoculation he observed gradual onset of dryness of the throat, which was later followed by soreness of the throat, dry cough and malaise. On the 2nd day of illness he complained of feverishness, loss of appetite, aching of the eye-balls, sneezing and "stuffiness" of the nose. Physical examination revealed tender cervical lymph nodes and minimal injection of the nasal and pharyngeal mucosa. On the $3 \mathrm{rd}$ day there was improvement in constitutional symptoms but little change in throat or nasal symptoms; in addition the cough became productive of mucoid sputum. From the 4th to 8th day of illness he noted substernal discomfort during coughing. The nasal symptoms persisted until the 10th day. Cough decreased in amount and intensity, finally disappearing on the 12th day, 18 days after inoculation. Pulmonary infiltration was not demonstrated by auscultation or by roentgenography. Roentgenograms of the paranasal sinuses showed no evidence of acute or chronic infection. Recovery was uneventful. Bacteriological examinations showed no change in flora of the throat; serological examinations were non-contributory.

\section{Inoculation of S-CC filtrate}

Fourteen volunteers were inoculated with S-CC filtrate after a control isolation period of 25 days (Group C, Table II). The donor of this inoculum had experienced a moderately severe febrile respiratory illness in which nasal symptoms, coryza and cough were associated with constitutional symptoms. The clinical course of illness in this donor is given below and in Figure 2.

OL, a 35-year-old laboratory officer, had been well for at least a month when on the morning of April 23 he observed coryza, cough and substernal soreness. He reported for duty but felt unwell because of malaise, fever, coryza and continued cough which was productive intermittently of greenish-yellow sputum. In the afternoon, the malaise became worse. By evening he felt "grippy" and observed a dull frontal headache. The oral temperature was $100.2^{\circ} \mathrm{F}$. The following morning there were dryness of eyes, mouth, throat and lips and diminution of nasal symptoms. Physical examination revealed a temperature of $99.4^{\circ} \mathrm{F}$, mild hypertrophy of the pharyngeal lymph follicles, edema and injection of the nasal mucosa without discharge. The lungs were clear. Roentgenograms of the lungs and paranasal sinuses showed no acute or chronic pathological changes. Trans-illumination of the sinuses was normal; a consultant found no evidence or allergic rhinitis. The temperature rose to $101.2^{\circ} \mathrm{F}$. on the evening of April 24, the 2nd day.

On the morning of the 3rd day the most prominent symptoms were malaise, feverishness, headache, anorexia, obstruction of the nares and cough. Physical examination revealed profuse serous nasal discharge. By the 4th day he was considerably improved; coughing was less fre- 


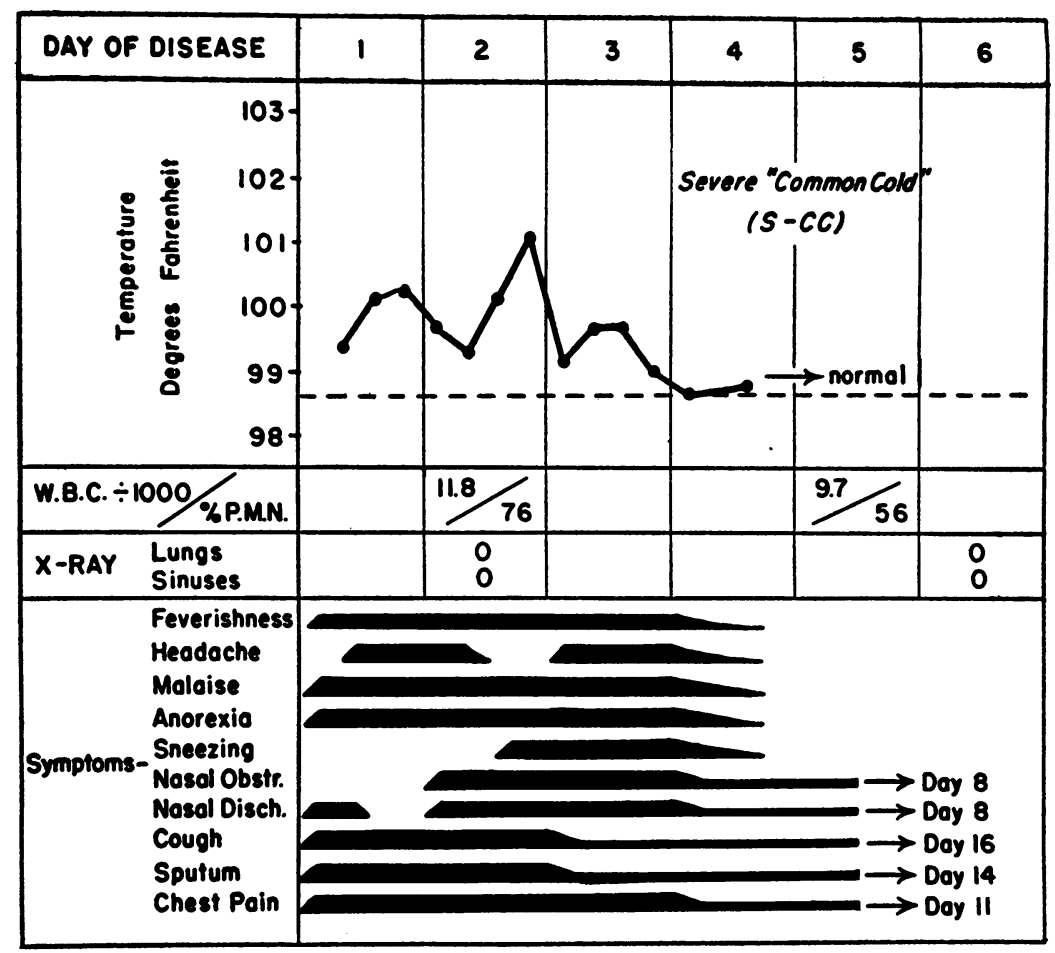

Fig. 2. Clinical Chart of Donor Whose Illness was Termed Severe "Common Cold" (S-CC)

quent and there was gradual decrease in nasal symptoms and signs. Roentgenograms of the chest and sinuses on the 6th day showed no pathological changes. Convalescence was prolonged.

The total leukocyte count on the 2nd day was 11,800 ; on the 5th day the count had decreased to 9,700. Polymorphonuclear leucocytes constituted 76 and 56 per cent, respectively, of the differential formulae. Cultures of the throat and sputum revealed pneumococcus, type 11. $H$. hemolyticus was isolated from throat washings. Samples of acute and convalescent sera showed no increase in antibody titer to sheep cells, streptolysin " $O$," group " $O$ " human erythrocytes, or influenza viruses $A$ and $B$.

Of the 14 subjects given S-CC inoculum, nine became ill with mild to moderately severe respiratory infection (Table II). None of this group developed roentgenographic evidence of primary atypical pneumonia.

In contrast with the finding in the ARD group, all patients developed illness within 24 to 48 hours after inoculation of S-CC filtrate. The clinical pattern was featured by sneezing, nasal obstruction and objective evidence of coryza. Because of the prominence of nasal symptoms and signs there was usually little difficulty encountered at the bedside in distinguishing this type of illness from that which followed the ARD inoculum. The duration of illness, furthermore, was more prolonged. Symptoms were present for from 4 to 7 days in 4 patients, from 9 to 13 days in 5 . The type and course of illness resulting from S-CC inoculum resembled that of naturally acquired cases of the "common cold." An example is presented in the following case report:

Case No. RP3-236. This 22-year-old volunteer had experienced rare head colds of 2 weeks' duration during the past few years. He suffered occasionally from frontal headaches and, during most of the preceding year, from slight nasal congestion and post-nasal discharge. His last previous respiratory infection occurred during the spring of 1945 with symptoms lasting for only 1 day. During the 25-day control period of isolation he was free of respiratory symptoms.

Inoculated on June 11, he first noted an abrupt onset of illness at 6 p.m. on June 12. The incubation period was calculated to be not less than 27 hours nor more than 33 hours. The initial symptoms were excessive sneezing, nasal discharge and increased post-nasal drip. Later that evening he noted generalized weakness, dull cranial discomfort and mild sore throat. The following day cough and feverishness were present, and physical examination disclosed only slight injection of the pharynx. The temperature rose to $100.2^{\circ} \mathrm{F}$. on the afternoon of the 2 nd day 
of illness. On the 3rd day (June 14) the temperature returned to normal, headache persisted, but other constitutional symptoms were absent. Local symptoms, however, were prominent and consisted of sneezing, nasal obstruction and discharge, dry and sore throat, hoarseness and dry cough. Physical examination at this time revealed nasal obstruction, thin serous discharge from the nares and slight injection of the pharynx. The lungs were clear. The subsequent course of illness was characterized by improvement in nasal symptoms and signs and gradual diminution of cough which was no longer present after the 13th day. Roentgenograms of the chest showed no pulmonary infiltration at any time. Sinus films were clear before as well as 2 weeks after inoculation.

The leukocyte counts, differential formulae, and erythrocyte sedimentation rates were within normal limits. Serological tests on acute and convalescent sera showed no antibodies which were diagnostic of influenza, infectious mononucleosis, primary atypical pneumonia or streptococcal infection. Cultures of the throat showed Betahemolytic streptococcus, Group D, and pneumococcus, type 3, both of which were isolated repeatedly before as well as after inoculation.

\section{Inoculation of CC filtrate}

After an isolation period of 17 days, 10 volunteers were given CC filtrate obtained from a donor who had a mild afebrile respiratory illness charac- terized principally by coryza. This illness was considered to resemble the "common cold" (Group D, Table II). During convalescence from his infection the donor developed cold hemagglutinins in the serum in low titer. The course of illness in this patient is shown in the following case report and in Figure 3.

MI, a 29-year-old medical officer, first observed onset of respiratory disease on May 11, 1945. The first symptoms were dry throat and slight burning and irritation of the nose. Later in the day there was watering of the eyes. The following morning sneezing, nasal obstruction and coryza were prominent symptoms. The nasal discharge was copious and serous in character. Mild dysphonia also was present for a short period. Constitutional symptoms, except for fatigability, were absent. He carried on with his normal duties. Physical findings were confined to congestion and edema of the nasal mucosa. Roentgenograms of the chest and sinuses were interpreted as being normal.

The maximum temperature did not exceed $99^{\circ} \mathrm{F}$. Nasal obstruction and discharge were the most prominent features of illness. The appearance of the nasal mucosa did not suggest an allergic rhinitis. Cough was present for 2 days but was non-productive. No rales were audible in the lungs at any time.

A single total leukocyte determination showed 10,500 cells with normal differential distribution. Cold hemag-

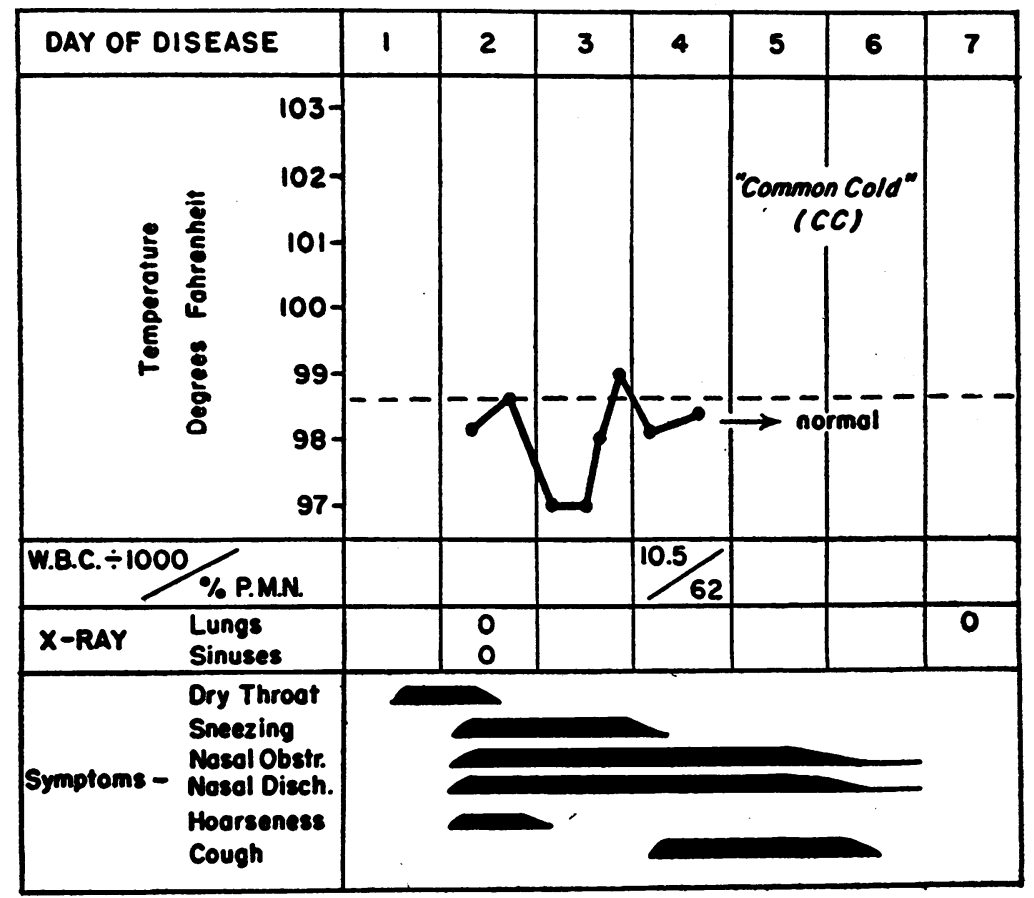

Fig. 3. Clinical Chart of Donor Whose Illness was Termed "Common Cold" (CC) 
glutinin titers were as follows: 2nd day, $<8$; 9th day, 32; 16 th day, $<8 ; 23$ rd day, 8 . Antistreptolysin, heterophile and influenza antibody studies showed no diagnostic increases in titer.

Six of the 10 subjects became ill following the inoculation of CC filtrate (Table II). The illnesses were not associated with fever, were mild in character and were featured by the presence of nasal symptoms and signs resembling those of the "common cold." None of the patients developed pulmonary infiltration or cold hemagglutinins.

Onsets of illness occurred approximately 24 hours after inoculation in 3 cases, on the 2 nd day in 2 cases, and the 4th day in 1 case. Illness in these patients usually began abruptly with the development of sneezing, nasal obstruction, and coryza in association with constitutional symptoms of mild degree. In 2 patients, dry or sore throat and cough were also early symptoms. In 2 patients, hoarseness was noted. Constitutional symptoms of chilliness, feverishness, headache, malaise or weakness were observed by 5 of the 6 cases but were of short duration.

Abnormal physical signs in the respiratory tract, except for obvious nasal obstruction and discharge, were minimal. Injection of the soft palate was not encountered and signs of inflammation of the pharynx (injection or lymphoid hyperplasia) were present in 3 cases. Rales were not audible. The illness in one patient, representative of the group, is given in the following case report.

Case No. RP4-321. A 30-year-old male had had "influenza" in January 1944. He usually experienced 2 to 3 respiratory infections each winter lasting about 1 week and manifested by sore throat, nasal congestion and coryza. There had been no illness of this type in the previous 4 months. During the pre-inoculation period of isolation he was well.

On July 28, at 2 p.m., approximately 30 hours after the first inoculation, he noted abrupt onset of excessive sneezing, nasal obstruction and coryza. Later that day he observed myalgia and postorbital aching. Dry cough and hoarseness were intermittently present during the first 12 hours. The following day, in addition to the above symptoms, he observed headache, a dry, sore throat and substernal aching. Physical examination revealed moderate nasal obstruction and clear serous discharge.

On the 3rd day (June 30) the constitutional symptoms were no longer present, the nasal symptoms were unchanged, post-nasal "drip" was noted and the cough was productive of a slight amount of mucoid sputum. Prominent lymphoid follicles on the pharynx were observed for the first time on this date. The subsequent course was characterized by rapid subsidence of all symptoms and signs. The clinical course of illness lasted 5 days. There were no signs of pulmonary infiltration. Recovery was uneventful.

The total and differential leukocyte counts and erythrocyte sedimentation rate showed no significant change from normal following inoculation. Cold hemagglutinins were not present in significant titer, all specimens showing titers of $<8$. Bacteriological study of the throat flora showed no significant change as a result of inoculation or of illness.

\section{Inoculation of Br-AP filtrate}

After a control isolation period of 16 days, a group of 10 volunteers was given filtrate $\mathrm{Br}-\mathrm{AP}$ (Group E, Table II). The illness in this donor was more severe than that experienced by any of the other donors. The symptoms, physical signs, clinical course and serological findings were consistent with the diagnosis of primary atypical pneumonia. Roentgenographic evidence of pulmonary infiltration, however, was lacking. The course of illness is given in the following case history and shown graphically in Figure 4.

BA, a 35-year-old soldier with 1 month of Army service, was admitted to the hospital on April 30, 1945. On the afternoon of admission there was an abrupt onset of chilliness, feverishness, generalized aching, weakness and dry cough. Later, headache was noted. The temperature was $100.8^{\circ} \mathrm{F}$., the pulse, 80 , and respirations, $20 \mathrm{per}$ minute. Physical examination the next day revealed a moderately ill patient whose soft palate and pharynx were injected. The lungs at this time were clear to percussion and auscultation and roentgenograms of the chest and sinuses were normal. During the 2nd day of disease the temperature rose to a maximum of $103.5^{\circ} \mathrm{F}$., the constitutional symptoms continued, cough persisted and was productive of a small amount of thick yellow sputum. On the 3rd day, the patient was still moderately ill, the temperature reaching a maximum of $104^{\circ} \mathrm{F}$. Fine rales were audible for the first time at the base of the left lung. A roentgenogram of the chest on the 4th day was clear. Rales continued to be heard at the left base, and subsequently, at the right base, until the 6 th day. The temperature fell by lysis, reaching normal on the 6th day. Cough and sputum continued until the 10th day.

The total leukocyte and differential counts were normal. Throat cultures showed Hemophilus influenzae and $H$. hemolyticus. From throat washings and sputa, the following organisms were isolated: pneumococcus, types 10,14 and $29 ; H$. influenzae and $H$. hemolyticus. Cold hemagglutinins were present in the convalescent sera during the 3 rd week in a titer of 16 ; blood taken during the acute illness showed a titer of $<8$. Heterophile antibody tests, antistreptolysin determinations and agglutinin-inhibition tests for influenza viruses A and B showed no diagnostic increases in titers. 


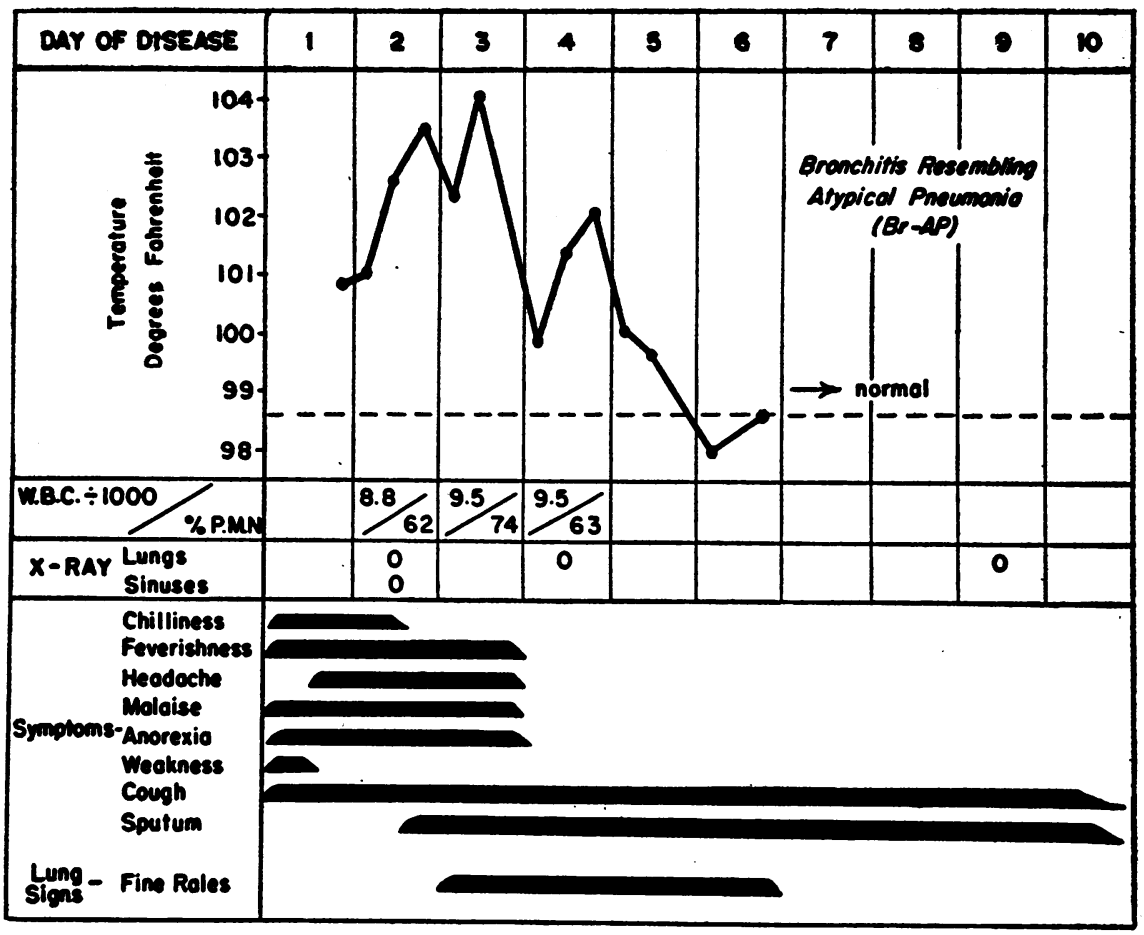

Fig. 4. Clinical Chart of Donor Whose Illness was Termed Bronchitis Resembling Atypical Pneumonia (Br-AP)

Of the 10 volunteers receiving $\mathrm{Br}-\mathrm{AP}$ filtrate, 4 developed minor respiratory illnesses (Table II). Onsets of disease in these patients were observed $2,3,3$ and 7 days, respectively, after inoculation. The illnesses were mild; fever was not observed in any of the patients. Auscultatory or roentgenographic evidence of pulmonary infiltration was not detected in any of those with illness.

Constitutional symptoms of feverishness, headache and malaise were present in only 1 patient. Two patients experienced sore throat as the initial symptom; the remaining 2 , nasal symptoms. Hoarseness was noted in 2 cases. Cough was not observed in any of the 4 who became ill.

Physical findings were minimal and consisted of tender cervical lymph nodes (1 case), nasal injection and obstruction ( 2 cases), pharyngeal injection (1 case) and pharyngeal lymphoid hyperplasia (2 cases).

No characteristic clinical pattern was evident in these cases. None of the illnesses was as severe as that of the donor of the inoculum.

\section{CLINICAL CORRELATIONS}

Comparison of the types of illness observed in each of the experimental groups revealed many clinical features which were common to all groups. Nevertheless, certain features such as nasal symptoms and signs, were more prominent in some groups than others. For purposes of increasing the material available for analysis, 6 cases of illness from the second half of the study are included (26). Four of these illnesses were induced by reinoculation of 5 men of the control group with filtrate S-CC, and the other 2 illnesses followed the inoculation of 5 men with filtrate ARD (see Figure 1 in the following paper [26]). Thus, clinical correlations were made from the following material : 14 cases, filtrate ARD; 13 cases, filtrate S-CC; 6 cases, filtrate CC; and 4 cases, filtrate $\mathrm{Br}-\mathrm{AP}$.

Incubation period. The sharp difference in incubation periods observed in the groups inoculated with filtrate ARD and S-CC is readily seen in Figure 5. Although the number of cases in the CC 


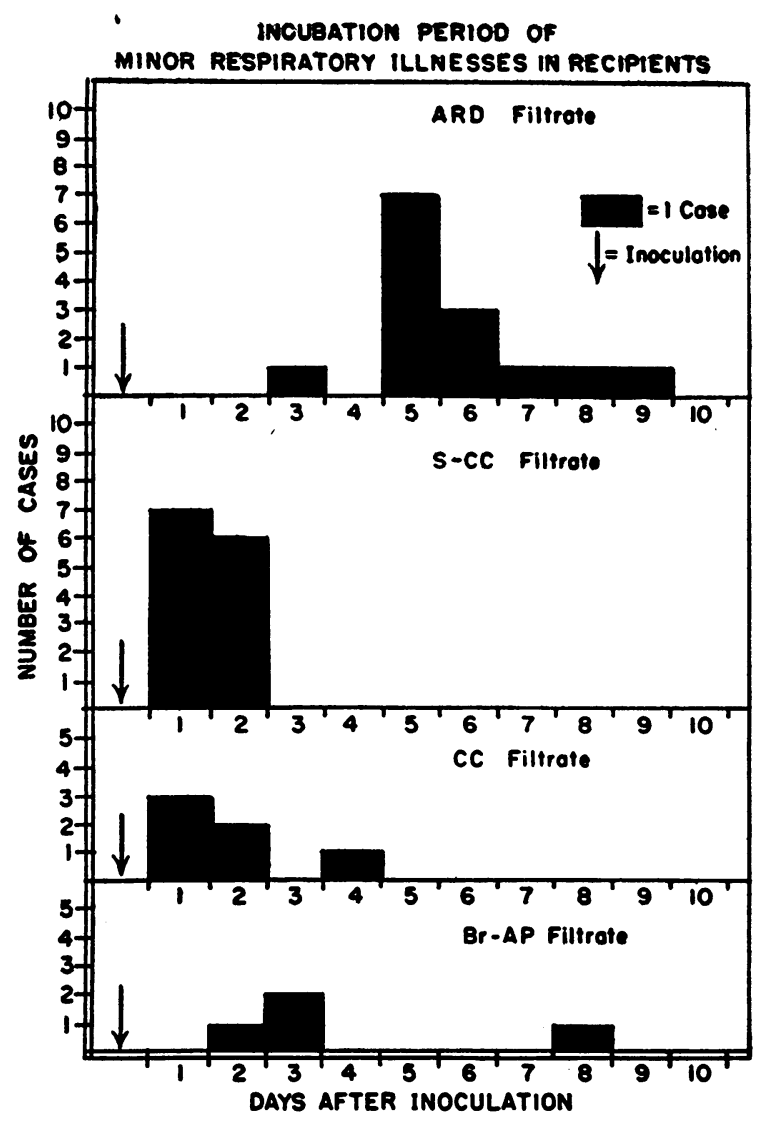

Fig. 5. Incubation Period of Minor Respiratory IllNESSES IN RECIPIENTS OF THE 4 INOCUla

See Table I and text for explanation of code designations ARD, S-CC, CC, and Br-AP.

group is small, 5 of the 6 cases had onsets on the 1 st or 2 nd day after inoculation. In this respect and in other features which will be pointed out below, the CC and S-CC groups were similar. The incubation period in the $\mathrm{Br}-\mathrm{AP}$ group was not clearly defined because of the small number of illnesses.

Symptomatology. The total frequency of symptoms is shown in Table III. Only slight differences are apparent for each symptom among the various diagnostic groups. With respect to daily frequency and time of appearance of nasal and throat symptoms, however, further analysis revealed certain differences between the ARD and S-CC groups (Figure 6). Nasal symptoms (sneezing, obstruction and discharge) tended to develop earlier, that is, within the first 48 hours from onset and were present in greater day-by-day
TABLE III

Total frequency of symptoms in 37 cases of experimentally induced minor respiratory illness

\begin{tabular}{|c|c|c|c|c|}
\hline \multirow{2}{*}{ Symptom } & \multicolumn{4}{|c|}{$\begin{array}{l}\text { Frequency of symptoms in } \\
\text { various groups* }\end{array}$} \\
\hline & $\begin{array}{c}\text { ARD } \\
(14 \\
\text { cases })\end{array}$ & $\begin{array}{c}\text { S-CC } \\
(13 \\
\text { cases })\end{array}$ & $\begin{array}{c}\mathrm{CC} \\
(6 \\
\text { cases })\end{array}$ & $\begin{array}{c}\mathrm{Br}-\mathrm{AP} \\
(4 \\
\text { cases })\end{array}$ \\
\hline $\begin{aligned} & \text { Constitutional: } \text { Chilliness } \\
& \text { Feverishness } \\
& \text { Headache } \\
& \text { Malaise } \\
& \text { Anorexia } \\
& \text { Weakness }\end{aligned}$ & $\begin{array}{l}0 \\
1 \\
7 \\
4 \\
3 \\
2\end{array}$ & $\begin{array}{l}0 \\
4 \\
8 \\
3 \\
1 \\
3\end{array}$ & $\begin{array}{l}1 \\
3 \\
4 \\
4 \\
0 \\
1\end{array}$ & $\begin{array}{l}0 \\
1 \\
1 \\
1 \\
0 \\
0\end{array}$ \\
\hline $\begin{array}{l}\text { Local: Sneezing } \\
\text { Nasal obstruction } \\
\text { Nasal discharge } \\
\text { Dry throat } \\
\text { Sore throat } \\
\text { Hoarseness } \\
\text { Cough } \\
\text { Sputum } \\
\text { Chest pain }\end{array}$ & $\begin{array}{r}4 \\
10 \\
8 \\
6 \\
10 \\
5 \\
6 \\
5 \\
3\end{array}$ & $\begin{array}{r}8 \\
11 \\
12 \\
8 \\
7 \\
8 \\
9 \\
4 \\
4\end{array}$ & $\begin{array}{l}5 \\
6 \\
6 \\
5 \\
2 \\
2 \\
3 \\
1 \\
2\end{array}$ & $\begin{array}{l}1 \\
2 \\
2 \\
0 \\
3 \\
2 \\
0 \\
0 \\
0\end{array}$ \\
\hline
\end{tabular}

* See Table I and text for explanation of code designations.

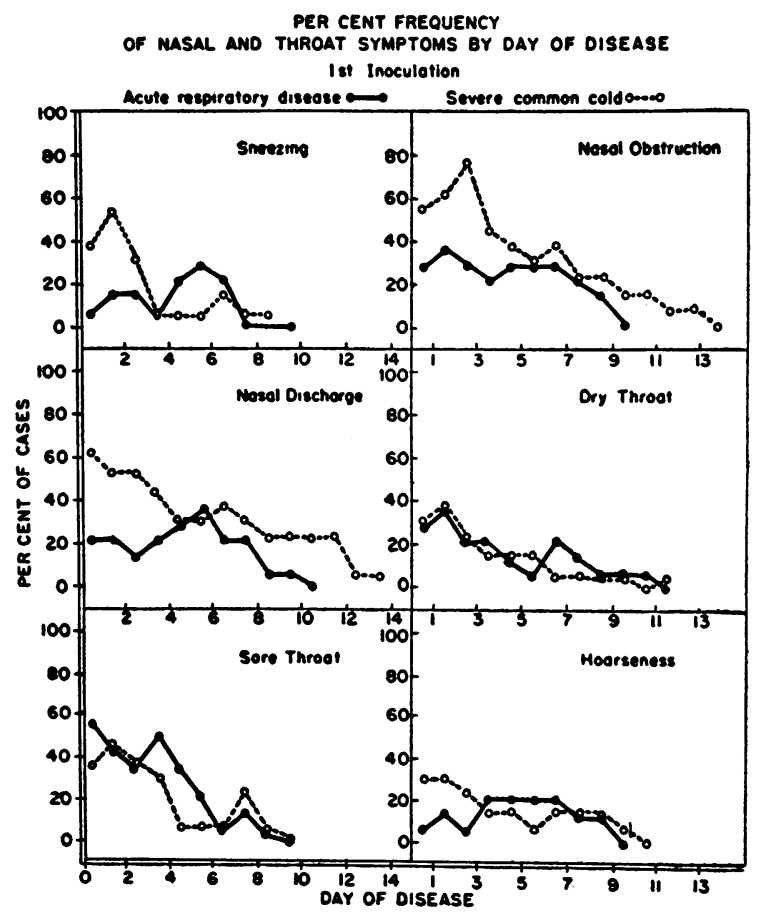

Fig. 6. DaIly Frequency and Time of Appearance of Nasal and Throat Symptoms in Minor RespiraTORY Diseases EXPERIMENTALLY INDUCED by ARD AND S-CC Inocula 
frequency, in the S-CC group than in the ARD group. These findings substantiated clinical impressions gained at the time the patients were ill. Throat symptoms (dry and sore throat), on the other hand, appeared in each group at approximately the same time and were present in the same daily frequency during the course of disease. The $\mathrm{CC}$ and $\mathrm{Br}-\mathrm{AP}$ groups are omitted from consideration because of the small number of cases.

The number of nasal symptoms (sneezing, obstruction and discharge) observed during the first 48 hours also showed differences among the groups (Table IV). The presence of 2, or of all 3 nasal symptoms was encountered more often in those men in the S-CC and CC groups. Conversely, multiple nasal symptoms were experienced infrequently by those in the ARD group.

TABLE IV

Total number of nasal symptoms present within 48 hours after onset in various diagnostic groups

\begin{tabular}{c|c|c|c}
\hline \multirow{2}{*}{$\begin{array}{c}\text { Number of nasal } \\
\text { symptoms* }\end{array}$} & \multicolumn{3}{|c}{ Groupt } \\
\cline { 2 - 4 } & ARD & S-CC & CC \\
\hline None & 4 & 3 & 0 \\
One & 7 & 3 & 0 \\
Two & 3 & 1 & 2 \\
Three & 0 & 6 & 4 \\
\hline Total cases & 14 & 13 & 6 \\
\hline
\end{tabular}

* Sneezing, obstruction and discharge.

† See Table I and text for explanation of code designations.

The duration of throat complaints and nasal symptoms was approximately the same in the various groups. Obstruction and discharge tended to persist somewhat longer in the $\mathrm{S}-\mathrm{CC}$ and $\mathrm{CC}$ groups.

The relation of nasal symptoms to nasal signs and throat symptoms to signs during the first 2 days of illness is shown in Table V. In general, better correlation was found between nasal symptoms and signs in groups $\mathrm{S}-\mathrm{CC}$ and $\mathrm{CC}$, in which coryza was a prominent feature, than occurred in group ARD. Conversely, more correlation was found between throat symptoms and signs in the ARD group, in which sore throat was a characteristic feature, than was shown in the other groups.

Physical signs. The total frequency of physical signs at any time during illness is shown in Table VI. It is apparent that nasal signs were frequent
TABLE $\mathbf{V}$

The relation of nasal symptoms and signs and throat symptoms and signs during first 48 hours of illness in various diagnostic groups

\begin{tabular}{|c|c|c|c|c|c|c|}
\hline \multirow{3}{*}{ Physical signs } & \multicolumn{6}{|c|}{ Symptoms* } \\
\hline & \multicolumn{2}{|c|}{$A R D \S$} & \multicolumn{2}{|c|}{$\mathrm{S}-\mathrm{CC} \&$} & \multicolumn{2}{|c|}{$\mathrm{CC} \&$} \\
\hline & Present & Absent & Present & Absent & Present & Absent \\
\hline
\end{tabular}

Nasal symptoms

\begin{tabular}{c|l|l|l|l|l|l}
\hline Nasal signs & & & & & & \\
Present & 2 & 2 & 5 & 2 & 4 & 2 \\
Absent & 8 & 2 & 5 & 1 & 0 & 0 \\
\hline
\end{tabular}

Throat symptoms

\begin{tabular}{c|l|l|l|l|l|l}
\hline Throat signs $\ddagger$ & & & & & & \\
Present & 7 & 1 & 1 & 0 & 0 & 0 \\
Absent & 4 & 2 & 8 & 4 & 4 & 2 \\
\hline
\end{tabular}

* Symptoms: Nasal = Sneezing, obstruction or discharge. Throat $=$ Dryness or soreness.

$\dagger$ Nasal signs $=$ Injection, obstruction or discharge.

$\ddagger$ Throat signs = Injection of a soft palate, injection of pharynx or lymphoid hyperplasia of pharynx.

$\$$ See Table I and text for explanation of code designations.

and that signs referable to the throat were minimal. The percentage frequency of nasal and throat signs of any degree by day of disease is shown in Figure 7 for groups ARD and S-CC. The other 2 groups are omitted from this analysis because of the small number of cases. Differences between the 2 groups were most marked in the case of nasal obstruction and discharge.

TABLE VI

Total frequency of physical signs in 37 cases of experimentally induced minor respiratory illness

\begin{tabular}{|c|c|c|c|c|}
\hline \multirow[b]{2}{*}{ Physical signs } & \multicolumn{4}{|c|}{$\begin{array}{c}\text { Frequency of physical signs } \\
\text { in various groups* }\end{array}$} \\
\hline & $\begin{array}{c}\text { ARD } \\
\text { (14 } \\
\text { cases) }\end{array}$ & $\begin{array}{c}S-C C \\
(13 \\
\text { cases) }\end{array}$ & $\begin{array}{c}\mathrm{CC} \\
(6 \\
\text { cases) }\end{array}$ & $\begin{array}{c}\mathrm{Br}-\mathrm{AP} \\
\text { (4 } \\
\text { cases) }\end{array}$ \\
\hline $\begin{array}{c}\text { Nasal: Injection } \\
\text { Obstruction } \\
\text { Discharge } \\
\text { Soft palate: Injection } \\
\text { Pharynx: Injection } \\
\text { Lymphoid hyperplasia } \\
\text { Exudate } \\
\text { Cervical lymph nodes: Enlarged } \\
\end{array}$ & $\begin{array}{r}8 \\
8 \\
10 \\
4 \\
5 \\
5 \\
0 \\
2 \\
5\end{array}$ & $\begin{array}{r}6 \\
10 \\
11 \\
1 \\
3 \\
3 \\
0 \\
0 \\
3\end{array}$ & $\begin{array}{l}1 \\
5 \\
6 \\
0 \\
1 \\
2 \\
0 \\
0\end{array}$ & $\begin{array}{l}2 \\
2 \\
1 \\
1 \\
0 \\
1 \\
2 \\
0 \\
0 \\
1\end{array}$ \\
\hline
\end{tabular}

* See Table I and text for explanation of code designations. 


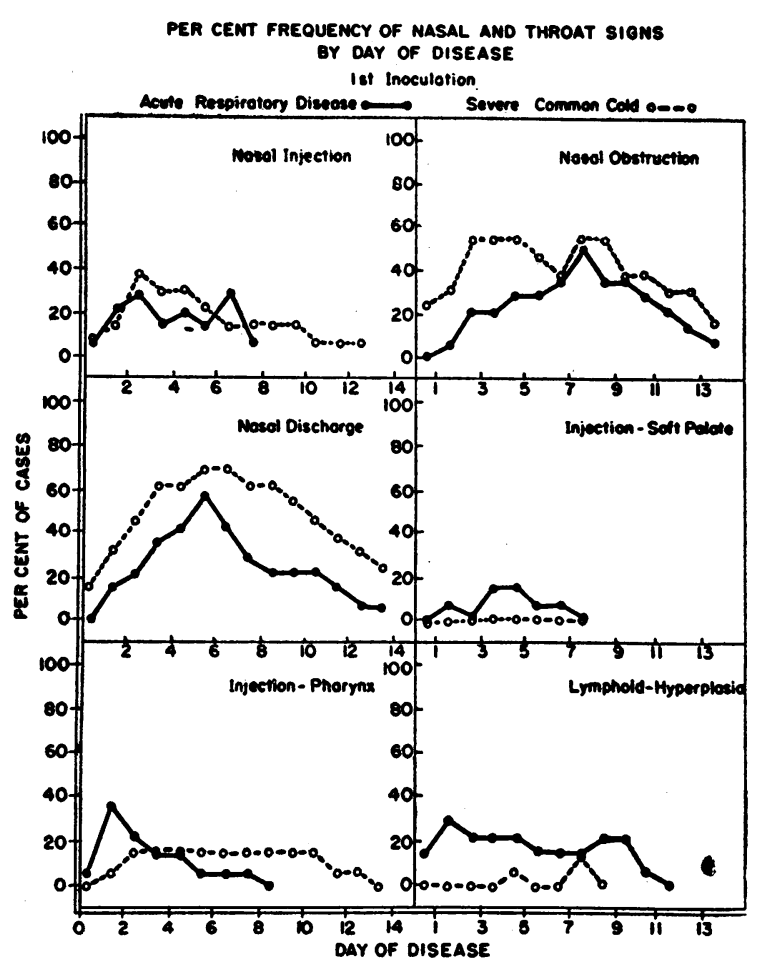

Fig. 7. Danly Frequency and Time of Appearance of Nasal and Throat Signs in Minor Respiratory Diseases Experimentally IndUCEd by ARD AND S-CC INOCULA

Fever. Fever was not a conspicuous clinical feature of illness in the majority of the volunteers (Table VII). Only 2 individuals, both of whom received S-CC inoculum, developed temperatures of $100^{\circ} \mathrm{F}$. or more. Maximum temperatures in the other groups did not exceed $99.8^{\circ} \mathrm{F}$. The median febrile curves were essentially normal in the ARD and S-CC groups. Slightly higher tem-

TABLE VII

Febrile response in 37 cases of experimentally induced minor respiratory illness

\begin{tabular}{|c|c|c|c|c|c|}
\hline \multirow{2}{*}{ Group } & \multirow{2}{*}{$\begin{array}{c}\text { Total } \\
\text { cases } \\
\text { with } \\
\text { illness* }\end{array}$} & \multicolumn{3}{|c|}{ Number of cases with } & \multirow{2}{*}{$\begin{array}{c}\text { Maximum } \\
\text { fever } \\
\text { at any } \\
\text { time } \\
\text { (degrees } \\
\text { F.) }\end{array}$} \\
\hline & & $\begin{array}{l}\text { No fever } \\
99^{\circ} \mathrm{F} \text {. }\end{array}$ & ${ }_{99.2-99.8^{\circ}}^{\text {Fever }}$ & $\underset{100^{\circ} \text { F.+ }}{\text { Fever }}$ & \\
\hline $\begin{array}{l}\text { ARD } \\
\text { S-CC } \\
\text { CC } \\
\text { Br-AP }\end{array}$ & $\begin{array}{r}14 \\
13 \\
6 \\
4\end{array}$ & $\begin{array}{l}5 \\
3 \\
4 \\
1\end{array}$ & $\begin{array}{l}7 \\
7 \\
1 \\
3\end{array}$ & $\begin{array}{l}0 \\
2 \\
0 \\
0\end{array}$ & $\begin{array}{r}99.8 \\
100.2 \\
99.4 \\
99.8\end{array}$ \\
\hline
\end{tabular}

* 4 cases ( 2 in the ARD, 1 in the S-CC group and 1 in the CC group), showing intermittent low grade fever $\left(99\right.$ to $99.4^{\circ} \mathrm{F}$.) before and after inoculation, are omitted from analysis. In each case the temperature curve was not altered as a result of inoculation.
TABLE VIII

Average total leukocyte count in 57 volunticers in relation to inoculation and in 31 patients with illness in relation to onset

\begin{tabular}{|c|c|c|c|c|c|c|}
\hline \multirow{2}{*}{$\begin{array}{c}\text { Type } \\
\text { of } \\
\text { inoculum* }\end{array}$} & \multirow{2}{*}{$\begin{array}{c}\text { Number } \\
\text { inocu- } \\
\text { lated }\end{array}$} & \multicolumn{2}{|c|}{$\begin{array}{l}\text { Leukocyte count } \\
\text { (thousands) }\end{array}$} & \multirow{2}{*}{$\begin{array}{c}\text { Number } \\
\text { with } \\
\text { illness }\end{array}$} & \multicolumn{2}{|c|}{$\begin{array}{l}\text { Leukocyte count } \\
\text { (thousands) }\end{array}$} \\
\hline & & $\begin{array}{l}\text { Before } \\
\text { inocu- } \\
\text { lation }\end{array}$ & $\begin{array}{l}\text { After } \\
\text { inocu- } \\
\text { lation }\end{array}$ & & $\begin{array}{l}\text { Before } \\
\text { onset }\end{array}$ & $\begin{array}{l}\text { After } \\
\text { onset }\end{array}$ \\
\hline $\begin{array}{c}\text { Autogenous } \\
\text { ARD } \\
\text { S-CC } \\
\text { CC } \\
\text { Br-AP }\end{array}$ & $\begin{array}{r}9 \\
14 \\
14 \\
10 \\
10\end{array}$ & $\begin{array}{l}7.3 \\
7.6 \\
7.7 \\
7.0 \\
8.0\end{array}$ & $\begin{array}{l}7.1 \\
6.7 \\
7.0 \\
7.5 \\
7.6\end{array}$ & $\begin{array}{r}0 \\
12 \\
9 \\
6 \\
4\end{array}$ & $\begin{array}{l}7.6 \\
7.6 \\
6.9 \\
8.7\end{array}$ & $\begin{array}{l}6.5 \\
7.3 \\
7.4 \\
8.0\end{array}$ \\
\hline
\end{tabular}

* See Table I and text for explanation of code designations.

peratures, however, were found in the ARD group from the 5 th to the 8 th days, and in the S-CC group on the 2 nd day. These periods corresponded with the time when symptoms were present in the two groups of cases.

\section{LABORATORY STUDIES}

Hematology. Tabulation of the average total leukocyte count was made in each of the experimental groups according to inoculation and in relation to onset. A total of 381 individual leukocyte counts was made during the first study. As shown in Table VIII, the leukocyte counts in 3 of the 4 groups (ARD, S-CC and $\mathrm{Br}-\mathrm{AP}$ ) and in the control group fell to a slight extent; the average count in the remaining group (CC) increased. Similar differences were shown when the analyses were restricted to patients with illness. All of the average counts, however, were normal and within the limits of technical variation. Individual instances of leukocytosis or leukopenia were not encountered.

The relative percentage of polymorphonuclear neutrophils, lymphocytes, eosinophils and monocytes showed no significant change in any group either as a result of inoculation or after the development of illness.

The corrected erythrocyte sedimentation rate was normal ( 0.2 to 0.4$)$ in every subject both before as well as after inoculation.

Serology. A diagnostic increase in titer (4-fold or greater) of cold hemagglutinins was not encountered following inoculation in any of the subjects. Similarly, no increase in titer of hetero- 
phile antibodies, or of antibodies against streptolysin " $O$ " and influenza viruses $A$ and $B$ was shown in representative samples of serum.

Bacteriology. The results of bacteriological study of the throat flora, performed at 2-day intervals, were analyzed for the purpose of detecting any change in flora for any given organism in relation to time of inoculation or resultant illness. The organisms which formed the basis of the analysis were the Beta-hemolytic streptococcus, pneumococcus, $H$. influenzae and $H$. hemolyticus.

During the period of May 18 to 31, 37 individuals comprising the control, ARD, and S-CC groups were in quarantine prior to inoculation. After May' 31, when the control group received autogenous filtrates the other 2 groups were observed continuously and on June 8 and 11, respectively, they received initial inoculations. Thus, the interval, May 18 to 31 , provided a suitable period in which the bacteriological results could be compared within each of the groups. The interval, June 2 to 8 , was a period in which the bacteriological findings in the inoculated control group could be contrasted with those in the ARD group; similarly, comparisons were permitted between the control and S-CC groups during the period, June 2 to 10 . The results are given in Table IX. Marked fluctuations occurred in the frequency with which each of the 4 organisms was isolated during the period of quarantine, May 18 to 31 . No significant change in throat flora was observed in the control group as a result of having received autogenous filtrate.

The effect of inoculation on the pharyngeal flora of the ARD and S-CC groups is compared in Table $X$. The analysis was restricted to those individuals who experienced illness, and the results are contrasted with those obtained in the control group, the members of which had experienced no illness. It is apparent that before inoculation there was wide fluctuation in the percentage of individuals from whom any one of the organisms was isolated. Similar variations were evident after inoculation. Comparison of the results in the ARD and S-CC groups after inoculation with those of the control group showed slight differences; for example, in the case of the pneumococcus. However, these differences were of no greater order of

TABLE IX

Bacterislogical results in all individuals during period of quarantine and after inoculation of control group*

\begin{tabular}{|c|c|c|c|c|c|c|c|c|c|c|c|c|}
\hline \multirow{3}{*}{ Date } & \multicolumn{12}{|c|}{ Per cent of individuals harboring specified organisms } \\
\hline & \multicolumn{3}{|c|}{ B. H. S.t } & \multicolumn{3}{|c|}{ Pneumococcus } & \multicolumn{3}{|c|}{ H. influenrae } & \multicolumn{3}{|c|}{ H. hemolyticus } \\
\hline & Control & ARD & s-cC $t$ & Control & ARD & S-CC & Control & ARD & S-CC & Control & ARD & s-cc \\
\hline $\begin{array}{r}5 / 18 \\
19 \\
20 \\
21 \\
23 \\
25 \\
27 \\
. \quad 29 \\
31\end{array}$ & $\begin{array}{r}22 \\
22 \\
0 \\
25 \\
11 \\
11 \\
11 \\
11 \\
11\end{array}$ & $\begin{array}{r}9 \\
9 \\
0 \\
7 \\
21 \\
14 \\
31 \\
23 \\
27\end{array}$ & $\begin{array}{r}8 \\
25 \\
0 \\
25 \\
33 \\
21 \\
7 \\
7 \\
23\end{array}$ & $\begin{array}{l}11 \\
33 \\
33 \\
45 \\
33 \\
33 \\
67 \\
62 \\
56\end{array}$ & $\begin{array}{r}27 \\
8 \\
43 \\
36 \\
36 \\
43 \\
57 \\
57 \\
71\end{array}$ & $\begin{array}{r}25 \\
25 \\
33 \\
25 \\
8 \\
50 \\
43 \\
29 \\
57\end{array}$ & $\begin{array}{r}22 \\
0 \\
0 \\
12 \\
11 \\
22 \\
0 \\
22 \\
11\end{array}$ & $\begin{array}{r}18 \\
27 \\
14 \\
36 \\
38 \\
23 \\
8 \\
38 \\
27\end{array}$ & $\begin{array}{r}0 \\
8 \\
0 \\
58 \\
33 \\
29 \\
29 \\
57 \\
46\end{array}$ & $\begin{array}{r}44 \\
22 \\
0 \\
50 \\
67 \\
56 \\
44 \\
67 \\
78\end{array}$ & $\begin{array}{r}27 \\
18 \\
7 \\
21 \\
0 \\
36 \\
54 \\
43 \\
36\end{array}$ & $\begin{array}{r}42 \\
25 \\
0 \\
25 \\
42 \\
28 \\
50 \\
57 \\
54\end{array}$ \\
\hline
\end{tabular}

Inoculation of control group with autogenous filtrate $(5 / 31) \&$

\begin{tabular}{r|r|r|r|r|r|r|r|r|r|r|r|r}
\hline $6 / 2$ & 25 & 17 & 8 & 45 & 71 & 62 & 12 & 17 & 33 & 75 & 41 & 67 \\
4 & 12 & 15 & 15 & 33 & 50 & 43 & 12 & 31 & 23 & 100 & 62 & 62 \\
6 & 22 & 7 & 7 & 67 & 50 & 43 & 0 & 29 & 14 & 11 & 28 & 14 \\
8 & 22 & 21 & 21 & 45 & 36 & 43 & 0 & 7 & 21 & 44 & 7 & 28 \\
10 & 11 & & 15 & 45 & & 64 & 22 & & 31 & 67 & \\
\hline
\end{tabular}

* Figures represent specified percentage of individuals in any particular group showing the presence of specified organism,on each day. The presence of Beta-hemolytic streptococcus, $H$. influenzae and $H$. hemolyticus was identified on blood agar plates. Only the results of isolation of pneumococci by mouse inoculation are recorded.

B. H.S. = Beta-hemolytic streptococcus.

$\ddagger$ Control group $=9$ individuals; ARD group $=14 ; \mathrm{S}-\mathrm{CC}$ group $=14$; see Table I and text for explanation of code designations.

8 Figures in italics indicate results in inoculated group. 
TABLE $X$

Bacteriological results in those individuals developing illnesses, before and after inoculation with the ARD and $S-C C$ filtrates, and in the control group*

\begin{tabular}{|c|c|c|c|c|c|c|c|c|c|c|c|c|}
\hline \multirow{3}{*}{ Date } & \multicolumn{12}{|c|}{ Per cent of individuals harboring specified organisms } \\
\hline & \multicolumn{3}{|c|}{ B. H. S.* } & \multicolumn{3}{|c|}{ Pneumococcus } & \multicolumn{3}{|c|}{ H. influensae } & \multicolumn{3}{|c|}{ H. hemolyticus } \\
\hline & Control & ARD & $\mathrm{s}-\mathrm{CC}+$ & Control & ARD & S-CC & Control & ARD & S-CC & Control & ARD & s-CC \\
\hline $\begin{array}{r}5 / 18 \\
19 \\
20 \\
21 \\
23 \\
25 \\
27 \\
29 \\
31 \\
6 / 2 \\
4 \\
6 \\
8\end{array}$ & 22 & $\begin{array}{r}10 \\
11 \\
0 \\
8 \\
17 \\
8 \\
27 \\
17 \\
33 \\
20 \\
18 \\
8 \\
17\end{array}$ & $\begin{array}{r}12 \\
38 \\
0 \\
38 \\
38 \\
33 \\
11 \\
11 \\
25 \\
12 \\
22 \\
11 \\
33\end{array}$ & 45 & $\begin{array}{l}30 \\
10 \\
42 \\
42 \\
33 \\
42 \\
50 \\
50 \\
58 \\
67 \\
42 \\
42 \\
33\end{array}$ & $\begin{array}{r}25 \\
12 \\
38 \\
12 \\
0 \\
33 \\
33 \\
11 \\
56 \\
50 \\
45 \\
33 \\
45\end{array}$ & $\mathbf{0}$ & $\begin{array}{r}20 \\
33 \\
17 \\
42 \\
46 \\
27 \\
10 \\
46 \\
33 \\
20 \\
36 \\
33 \\
8\end{array}$ & $\begin{array}{r}0 \\
12 \\
0 \\
50 \\
37 \\
33 \\
33 \\
56 \\
62 \\
37 \\
11 \\
11 \\
0\end{array}$ & 44 & $\begin{array}{r}30 \\
22 \\
8 \\
25 \\
0 \\
33 \\
55 \\
33 \\
67 \\
40 \\
73 \\
25 \\
8\end{array}$ & $\begin{array}{r}25 \\
0 \\
0 \\
12 \\
37 \\
33 \\
45 \\
56 \\
50 \\
62 \\
56 \\
11 \\
33\end{array}$ \\
\hline
\end{tabular}

Inoculation of ARD group (6/8)*

\begin{tabular}{l|l|l|l|l|l|l|l|l|l|l|l|l}
\hline 10 & 11 & 0 & 33 & 45 & 25 & 56 & 22 & 36 & 22 & 67 & 18 & 33 \\
\hline
\end{tabular}

Inoculation of S-CC group (6/11)

\begin{tabular}{l|r|r|r|r|r|r|r|r|r|r|r|r}
\hline 12 & 33 & 8 & 33 & 22 & 36 & 67 & 11 & 17 & 0 & 33 & 17 & 11 \\
14 & 22 & 25 & 22 & 45 & 58 & 67 & 22 & 33 & 22 & 33 & 25 & 45 \\
16 & 22 & 25 & 57 & 38 & 42 & 45 & 11 & 17 & 57 & 56 & 50 & 43 \\
18 & 22 & 10 & 11 & 56 & 33 & 45 & 11 & 40 & 33 & 56 & 30 & 33 \\
20 & 22 & 17 & 33 & 56 & 42 & 56 & 22 & 33 & 44 & 67 & 25 & 56 \\
22 & 12 & 17 & 33 & 56 & 25 & 56 & 0 & 58 & 56 & 62 & 50 & 45 \\
24 & 14 & 18 & 11 & 22 & 67 & 56 & 14 & 36 & 22 & 57 & 46 & 67 \\
26 & 0 & 0 & 12 & 56 & 50 & 78 & 17 & 50 & 12 & 50 & 25 & 75 \\
28 & 0 & 9 & 11 & 89 & 50 & 67 & 11 & 18 & 11 & 11 & 9 & 33 \\
\hline
\end{tabular}

* For explanation of figures and abbreviations, see Legend, Table IX.

$\uparrow$ Control group $=9$ individuals; $A R D$ group $=12 ; S-C C$ group $=9$.

magnitude than were present during the control period.

\section{DISCUSSION}

The initial phase of this study was an attempt to demonstrate the transmission of "minor respiratory illnesses" (MRI) to human volunteers by the inoculation of filtered respiratory secretions obtained from 4 donor subjects whose illnesses appeared to differ in their clinical characteristics. Minor respiratory illnesses were induced by the inocula from all 4 of the donors and presumptive evidence was obtained for the existence of separate etiological "entities." Only 2 types of illness, however, could be distinguished. The first type, induced by the "acute respiratory disease" (ARD) filtrate, was characterized by prominence of pharyngeal involvement and an incubation period of 5 to 6 days. The second type, induced by both the "common cold" (CC) and "severe common cold" (S-CC) filtrates, was characterized chiefly by coryza and an incubation period of 24 to 48 hours. The illnesses induced by the inoculum from the fourth donor, whose infection was termed "bronchitis resembling atypical pneumonia" ( $\mathrm{Br}-\mathrm{AP})$, were too few in number and variable in character to permit classification. The etiology and clinical nature of these induced minor respiratory illnesses will be discussed briefly in this paper. In the following paper, which presents the second phase of the study, the differentiation of these entities on an immunological basis will be considered and the relationship of the illnesses to primary atypical pneumonia will be discussed.

Consideration of the results of the initial experiments in terms of etiology led to the tentative con- 
clusions that the illnesses induced in the volunteers were the direct results of inoculation of the various filtrates and were due to uncharacterized filtrable agents, presumably viruses, therein. Several types of data supported such conclusions: (1) Two distinct periods of "incubation" existed between the time of inoculation of 3 of the filtrates (ARD, S-CC and CC) and the onset of symptoms in the recipients. (2) Symptoms of respiratory disease did not follow the inoculation of a control group of 9 men with autogenous filtrates, thus excluding mechanical irritation and the excitation of latent agents as an explanation of the results. (3) There were no consistent alterations in the bacterial flora of the throat at any time, before or after inoculation, in the individuals of any group either with or without illness. The development of streptococcal antistreptolysins was not demonstrable in convalescent phase sera. (4) Serological tests excluded the influenza viruses $\mathrm{A}$ and $\mathrm{B}$ as causative agents. The recognized clinical variability of influenza and its experimental incubation period of 6 to 48 hours (27 to 30 ) made these tests necessary. Heterophile agglutinins could not be demonstrated. Finally, (5) the results of these experiments differed in 2 respects from those in which primary atypical pneumonia was transmitted (18), namely, $(a)$ pulmonary infltration was not demonstrable roentgenographically in any patient and $(b)$ the incubation periods were shorter. On these bases, therefore, it seemed reasonable to consider the 2 types of illness induced in the volunteers as separate and distinct virus diseases.

The nature of the infections resulting from the administration of $\mathrm{S}-\mathrm{CC}$ and $\mathrm{CC}$ inocula suggested that a virus similar to, if not identical with, that of the "common cold" virus was operative. Previous transmission experiments in volunteers (31 to 35$)$ and apes $(33,36,37)$ have demonstrated a coryza-like illness of short incubation period ( 8 to 70 hours) following the inoculation of filtered respiratory tract washings obtained from individuals with the "common cold." The data obtained in the present study confirm and extend these observations.

The evidence derived from the administration of ARD inoculum suggested that this filtrate contained an agent which was distinct from that of the "common cold" virus. The sharp difference in in- cubation period and, clinically, the paucity of nasal symptoms and the prominence of throat symptoms early in the course of disease, were the chief differential features. While such results have not been noted in previous transmission experiments (33, 34 ), it is of interest that a clinical and epidemiological study of acute minor respiratory diseases by Van Volkenburgh and Frost (8) suggested a "real difference" between cases of "sore throat" and those of "coryza" and "cough," which was "in accordance with the prevailing view that a considerable proportion of the cases of sore throat ordinarily encountered are not related to the common cold."

The small number of infections with variable incubation periods resulting from the inoculation of $\mathrm{Br}-\mathrm{AP}$ filtrate permitted no conclusions regarding the nature of the agent present in this inoculum. It was anticipated that this group of volunteers would develop moderately severe respiratory illnesses with a long incubation period (approximately 2 weeks), since the donor of the inoculum had a more severe form of respiratory disease which resembled primary atypical pneumonia. None of the recipients, however, developed an infection of comparable degree.

A feature of considerable interest in this study was the mild nature of the illnesses which followed the several types of inoculum. Objective signs of illness, such as fever, or constitutional symptoms were not uniformly observed in patients of the ARD, S-CC and Br-AP groups, as had been noted in the donors.

The explanation for the mildness of the illness is unknown. It seems possible that a combination of circumstances was responsible. On the basis of a history of previous respiratory disease, these individuals had apparently been susceptible to respiratory infections in their ordinary walks of life and presumably were susceptible at the time of inoculation. Several factors, however, may have been operative to increase their resistance. Although the men were isolated and restricted in activity, the living conditions were those generally considered to be favorable for good health, namely, adequate rest, good nutrition, absence of physical fatigue and over-exertion, etc. The investigations were purposely conducted during the summer months when respiratory infections in the general population are usually infrequent and uncompli- 
cated. The environmental temperature was relatively constant, so that the potentially adverse effects of dermal chilling $(38,39)$ and of meteorological changes $(40,41)$ were avoided. The factor of dosage may have been of importance, but cannot be evaluated. Thus the possibility exists that some of the illnesses would have been more severe had the conditions of the study permitted more variation in the environmental and host factors.

\section{SUM MARY}

Minor respiratory illnesses were transmitted to human volunteers by the use of bacteria-free filtrates of pooled nasal and pharyngeal washings obtained from 4 single donors. Two of the donors had experienced coryza-like illnesses (S-CC and CC), 1 had had an infection with sore throat as a principal symptom (ARD), and the fourth suffered from a more severe form of illness ( $\mathrm{Br}-\mathrm{AP}$ ) which clinically resembled primary atypical pneumonia. As a control group, 9 single donors were inoculated with autogenous filtered washings.

Two types of illness were induced; one was a coryzal-like infection developing after an interval of 24 to 48 hours and the other, an infection characterized by prominence of sore throat, minimal nasal symptoms and an incubation period of 5 to 6 days. These illnesses were clinically distinguishable. The control group which received autogenous filtrates experienced no illnesses. Primary atypical pneumonia did not develop in any of the subjects.

The results of these experiments indicate that at least 2 filtrable agents, presumably viruses, may induce minor respiratory illness in man.

\section{BIBLIOGRAPHY}

1. Dingle, J. H., Abernethy, T. J., Badger, G. F., Buddingh, G. J., Feller, A. E., Langmuir, A. D., Ruegsegger, J. M., and Wood, W. B., Jr., Primary atypical pneumona, etiology unknown. Am. J. Hyg., 1944, 39, 67.

2. Commission on Acute Respiratory Diseases, Epidemiology of atypical pneumonia and acute respiratory disease at Fort Bragg, North Carolina. Am. J. Pub. Health, 1944, 34, 335.

3. Bock, A. V., Clinical observations, complications, and treatment of acute upper respiratory tract infections. Ann. Int. Med., 1938, 12, 317.

4. The School Epidemics Committee, Epidemics in schools; an analysis of the data collected during the first five years of a statistical inquiry. Medical
Research Coumcil, Special Reports Series, No. 227, 1938, London, His Majesty's Stationery Office.

5. Murray, M. E., Atypical bronchopneumonia of unknown etiology possibly due to a filtrable virus. New England J. Med., 1940, 222, 565.

6. Reimann, H. A., and Havens, W. P., An epidemic disease of the respiratory tract. Arch. Int. Med., 1940, 65, 138.

7. Frost, W. H., and Gover, M., The incidence and time distribution of common colds in several groups kept under continuous observation. Pub. Health Rep., 1932, 47, 1815.

8. Van Volkenburgh, V. A., and Frost, W. H., Acute minor respiratory diseases prevailing in a group of families residing in Baltimore, Maryland, 19281930. Prevalence, distribution and clinical description of observed cases. Am. J. Hyg., 1933, 17, 122.

9. Frost, W. H., and Van Volkenburgh, V. A., The minor respiratory diseases as observed during the influenza epidemic of $1928-29$ and in a nonepidemic period. Am. J. Hyg., 1935, 21, 647.

10. Hare, R., Hamilton, J., and Feasby, W. R., Influenza and similar respiratory infections in a military camp over a period of 3 years. Canad. J. Pub. Health, 1943, 34, 453.

11. Kornblum, K., and Reimann, H. A., The roentgenological aspects of an epidemic of acute respiratory tract infection. Am. J. Roentgenol., 1940, 44, 333.

12. Commission on Acute Respiratory Diseases, Endemic exudative pharyngitis and tonsillitis: etiology and clinical characteristics. J. A. M. A., 1944, 125, 1163.

13. Commission on Acute Respiratory Diseases and Commission on Air-Borne Infections. A study of the effect of oiled floors and bedding on the incidence of respiratory disease in new recruits. Am. J. Hyg., 1946, 43, 120.

14. Commission on Acute Respiratory Diseases. Clinical patterns of undifferentiated and other acute respiratory diseases in Army recruits. Unpublished data.

15. Commission on Acute Respiratory Diseases, Acute respiratory disease among new recruits. Am. J. Pub. Health, 1946, 36, 439.

16. Commission on Acute Respiratory Diseases, The present status of the etiology of primary atypical pneumonia. Bull. N. Y. Acad. Med., 1945, 21, 235.

17. Commission on Acute Respiratory Diseases, An experimental attempt to transmit primary atypical pneumonia in human volunteers. J. Clin. Invest., 1945, 24, 175.

18. Commission on Acute Respiratory Diseases, The transmission of primary atypical pneumonia to human volunteers: I. Experimental methods; II. Results of inoculation; III. Clinical features; IV. Laboratory studies. Bull. Johns Hopkins Hosp., 1946, 79, 97. 
19. Rourke, M. D., and Ernstene, A. C., A method for correcting the erythrocyte sedimentation rate for variations in the cell volume percentage of blood. J. Clin. Invest., 1930, 8, 545.

20. Commission on Acute Respiratory Diseases, Cold hemagglutinins in primary atypical pneumonia and other respiratory infections. Am. J. M. Sc., 1944, 208, 742.

21. Hodge, B. E., and Swift, H. F., Varying hemolytic and constant combining capacity of streptolysins; influence on testing for antistreptolysins. J. Exper. Med., 1933, 58, 277.

22. Paul, J. R., and Bunnell, W. W., The presence of heterophile antibodies in infectious mononucleosis. Am. J. M. Sc., 1932, 183, 90.

23. Hirst, G. K., and Pickels, E. G., A method for the titration of influenza hemagglutinins and influenza antibodies with the aid of a photoelectric densitometer. J. Immunol., 1942, 45, 273.

24. Commission on Acute Respiratory Diseases, in collaboration with Mickle, W. A., Jr., and Oliver, T. J. Problems in determining the bacterial flora of the pharynx: I. Technique of examining a throat swab. Unpublished data.

25. Pike, R. M., An enrichment broth for isolating hemolytic streptococci from throat swabs. Proc. Soc. Exper. Biol. and Med., 1944, 57, 186.

26. Commission on Acute Respiratory Diseases, Experimental transmission of minor respiratory illness to human volunteers by filter-passing agents: II. Immunity on reinoculation with agents from two types of minor respiratory illness and from primary atypical pneumonia. J. Clin. Invest., 1947, 26, 974.

27. Smorodintseff, A. A., Tushinsky, M. D., Drobyshevskaya, A. I., Korovin, A. A., and Osetroff, A. I., Investigation on volunteers infected with the influenza virus. Am. J. M. Sc., 1937, 194, 159.

28. Henle, W., Henle, G., and Stokes, J., Jr., Demonstration of the efficacy of vaccination against influenza type $A$ by experimental infection of human beings. J. Immunol., 1943, 46, 163.

29. Francis, T., Jr., Pearson, H. E., Salk, J. E., and Brown, P. N., Immunity in human subjects artificially infected with influenza virus, type B. Am. J. Pub. Health, 1944, 34, 317.
30. Francis, T., Jr., Salk, J. E., Pearson, H. E., and Brown, P. N., Protective effect of vaccination against induced influenza A. J. Clin. Invest., 1945, 24, 536.

31. Kruse, W., Die Erreger von Husten und Schnupfen. Muench. Med. Woch., 1914, 61, 1547.

32. Foster, G. B., Jr., The etiology of common colds; the probable role of a filtrable virus as the causative factor: with experiments on the cultivation of a minute micro-organism from the nasal secretion filtrates. J. Inf. Dis., 1917, 21, 451.

33. Dochez, A. R., Shibley, G. S., and Mills, K. C., Studies in the common cold. IV. Experimental transmission of the common cold to anthropoid apes and human beings by means of a filtrable agent. J. Exper. Med., 1930, 52, 701.

34. Long, P. H., Doull, J. A., Bourn, J. M., and McComb, F., The etiology of acute upper respiratory infection (common cold). J. Exper. Med., 1931, 53, 447.

35. Andrewes, C. H., and Oakley, W. G., The common cold wins the first round. St. Bartholomew's Hospital Journal, 1933, p. 74.

36. Dochez, A. R., Shibley, G. S., and Mills, K. C., A study of acute infections of the respiratory tract in the ape. Proc. Soc. Exper. Biol. and Med., 1929, 26, 562 .

37. Shibley, G. S., Mills, K. C., and Dochez, A. R., Further consideration of the transmissibility of human upper respiratory infections (common cold) to the ape. Proc. Soc. Exper. Biol. and Med., 1929, 27, 59.

38. Hill, L., The science of ventilation and open-air treatment. Medical Research Council, Special Reports Series, No. 32, Part 1, 1919, London, His Majesty's Stationery Office.

39. Mudd, S., Grant, S. B., and Goldman, A., The etiology of acute inflammations of the nose, pharynx and tonsils. Ann. Otol. Rhinol. and Larnygol., 1921, $30,1$.

40. Van Loghem, J. J., An epidemiological contribution to the knowledge of respiratory diseases. J. Hyg., 1928, 28, 33.

41. Young, M., The influence of weather conditions on the mortality from bronchitis and pneumonia in children. J. Hyg., 1924, 23, 151. 